\title{
Connectivity and population repatriation: limitations of climate and input into the larval pool
}

\author{
Rhiannon L. Rognstad*, David S. Wethey, Thomas J. Hilbish \\ Department of Biological Sciences, University of South Carolina, 715 Sumter Street, Columbia, South Carolina 29208, USA
}

\begin{abstract}
We used climate-induced variation in fecundity of the barnacle Semibalanus balanoides to test the hypothesis that variation in adult input to the larval pool is a driver of connectivity among adult populations of coastal marine invertebrates. We predicted that cold winters will lead to high reproductive output and high recruitment by $S$. balanoides, while warm winters will result in low reproductive output and low recruitment. Following the cold winter of 2009 to 2010, larval recruitment was exceptionally high $\left(>6 \mathrm{~cm}^{2}\right)$ in Southwest England, resulting in a range expansion of over $100 \mathrm{~km}$. The following winter was also cold, and recruitment was again high. The winter of 2011 to 2012 was warm, and recruitment was low $\left(\sim 1 \mathrm{~cm}^{-2}\right)$ throughout Southwest England. These data indicate that recruitment and population connectivity are strongly linked to adult input to the larval pool. We analyzed winter temperature variation over the past 3 decades and found that warm winter temperatures over the 13 yr prior to this study likely led to frequent reproductive failure and the decline of $S$. balanoides in Southwest England. Continued warming in this region is likely to permanently exclude $S$. balanoides from this portion of its geographic range. This study illustrates an important role of adult input into the larval pool in controlling population connectivity in open marine ecosystems and also implicates climate variation in determining the range limit of a significant component of coastal ecosystems in Europe.
\end{abstract}

KEY WORDS: Connectivity $\cdot$ Semibalanus $\cdot$ Climate change $\cdot$ Recruitment $\cdot$ Biogeography

Resale or republication not permitted without written consent of the publisher

\section{INTRODUCTION}

In marine systems, many species are sedentary as adults, constraining connective processes to the early life stages. Adults in these populations are unlikely to be major contributors to the next generation at their particular location because larvae have the potential to be transported over wide geographic areas (Nathan 2001, Gilg \& Hilbish 2003, Pineda et al. 2009). Consequently, understanding the decline, maintenance, or new establishment of subpopulations requires knowledge of both local conditions and regional patterns of connectivity. Most studies of marine population connectivity focus on post-spawning processes, especially physical circulation, that describe the link between larvae and adults (Levin 2006). These include factors that determine whether larvae will be transported to a settlement site (Rumrill 1990), the number of settlers (Minchinton \& Scheibling 1991), or the transition from settlers to recruits (McGuinness \& Davis 1989, Menge 2000). Conversely, the reciprocal relationship, the link between adults and larval production, is much less well known because this requires enumerating the contribution of all adult populations that potentially contribute to the larval population at the geographic scale of larval dispersal (Hughes et al. 1999, 2000). In open marine systems with planktonic larvae, this would entail enumerating the larval production of all adult populations across spatial scales of 10 to $100 \mathrm{~km}$ (Gilg \& Hilbish 2003, Becker et al. 2007). Nonetheless, the few studies that have explored the relationship between adults and larval pool size indicate that variation in fecundity of adults is responsible for a large amount 
of variation in recruitment (Hughes et al. 2000, Reed et al. 2009, Burrows et al. 2010) and metapopulation growth (Carson et al. 2011).

In this study, we exploit a feature of the reproductive biology of the barnacle Semibalanus balanoides that creates annual variation in reproductive output at the spatial scale of larval dispersal to test the hypothesis that adult fecundity appreciably influences the size of the larval pool and population connectivity in open marine ecosystems. Reproduction in $S$. balanoides is inhibited by warm temperatures above 10 to $12^{\circ} \mathrm{C}$ (Barnes 1957a,b, 1963, Crisp \& Clegg 1960, Crisp \& Patel 1969); laboratory studies indicate that a period of 4 to $6 \mathrm{wk}$ at or below $10^{\circ} \mathrm{C}$ is necessary for reproduction (Crisp \& Patel 1969). Recruitment also has been observed to vary inversely to winter temperatures (Drévès 2001). These results suggest that greater reproductive output is expected when adult $S$. balanoides experience a cold winter than when warm conditions prevail. Sea surface temperature (SST) also varies at a broad spatial scale (25 to $100 \mathrm{~km}$ ) and, thus, is expected to simultaneously affect the reproductive output of all adult populations within a region. In this study, we test the hypothesis that annual variation in winter SST results in variation in adult reproduction, provisioning of the larval pool, and population connectivity at regional scales. We conducted this study on the English Channel coast of Southwest England because the abundance of $S$. balanoides in this region oscillates through time (Southward et al. 1995, Hawkins et al. 2003), and this species has been rare or absent from much of the region in the decade prior to 2010. The cold winters of 2009 to 2010 and 2010 to 2011 exceeded the physiological threshold where $S$. balanoides is expected to have high larval production, and the warm winter of 2011 to 2012 did not exceed the threshold; consequently, low larval production is predicted in this year.

\section{MATERIALS AND METHODS}

\section{Field work}

During early June of 2010 and 2011, 14 intertidal sites were sampled at approximately $10 \mathrm{~km}$ intervals, encompassing over $250 \mathrm{~km}$ of the coast of Southwest England (Fig. 1). During 2012, a subset of 11 of the sites was sampled. At each site, we sampled barnacle populations within the mid-tidal range where Semibalanus balanoides are found if present by haphazardly positioning quadrats within this zone. We

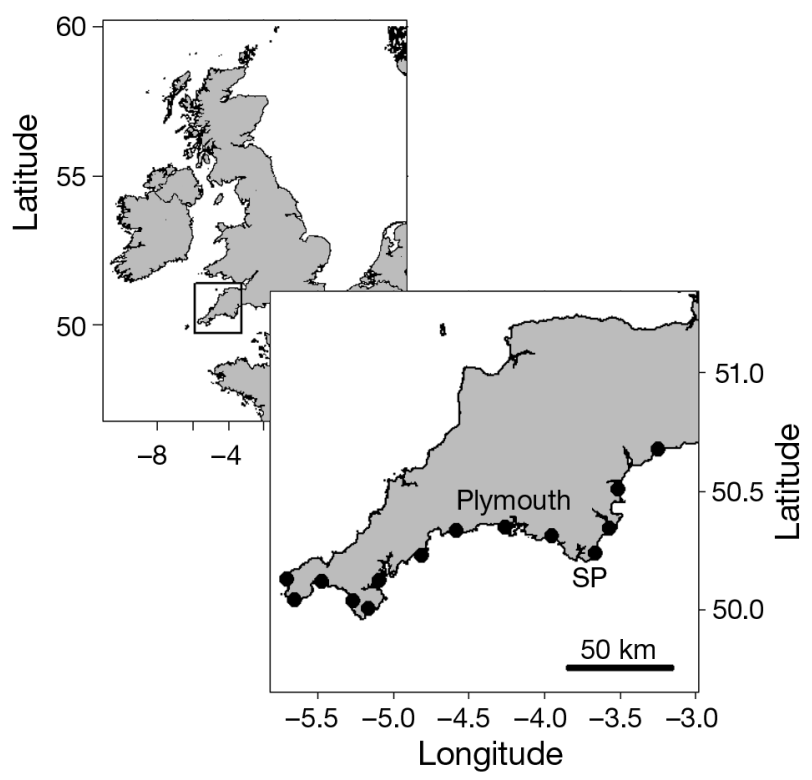

Fig. 1. Semibalanus balanoides. Study region and sampling sites in Southwest England. Photographic quadrats were taken at 14 sites $(\bullet)$ located in the intertidal zone of Devon and Cornwall during 2010, 2011, and 2012. From east to west, site locations are Sidmouth, Maidencombe, Dartmouth. Hallsands, Mothecombe, Whitsand Bay, Lansallos, Hemmick Beach, Maenporth, Kennack Sands, Poldhu, St. Michaels Mount, Porthcurno, and Cape Cornwall. The city of Plymouth is also shown. SP: Start Point

photographed barnacles attached to the substratum along with a metric tape for determining the size and density of barnacles in each sample. Sites selected for photographic sampling appeared representative of the location. If no individuals identifiable as $S$. balanoides could be located at a site after $30 \mathrm{~min}$ of searching, the species was assumed to be absent or very rare at the site, and a density of zero was recorded.

\section{Image analysis}

A subset of at least 5 images (out of 10 to 30) was selected for analysis from each site during each year. These images were included based on focus quality, as barnacles outside the focal plane could not be identified. Because of variation in the flatness of the underlying rock, the size of the available space in focus in each image varied; the countable area ranged from 5 to $155 \mathrm{~cm}^{2}$, with a mean quadrat size of $32.4 \mathrm{~cm}^{2}$. Images were imported into the open-source software ImageJ (Abramoff et al. 2004) for subsequent analysis. Semibalanus balanoides individuals were identified based on plate number and shape as 
described by Southward \& Crisp (1963). Differentiation of $S$. balanoides from other common intertidal species in the region, including Chthmalus stellatus, C. montagui, and Elminus modestus, is relatively straightforward, as $S$. balanoides has a diamondshaped operculum and 2 of its 6 shell plates are much narrower than the others (Southward 1976). Individuals were assigned to 1 of 2 age classes: young of the year (YOY) and adults. YOY are readily recognized by having white plates that are well defined, whereas adults are more stained and brown in color and typically have significant fusion and weathering of the plates. The metric tape in each of the photographic quadrats was used to calibrate the ImageJ measurement tool, which was subsequently used to calculate the average density of $S$. balanoides individuals of each age class at each site.

\section{Temperature and statistical analysis}

NOAA's optimally interpolated $1 / 4$ degree daily SST analysis data V2 (Reynolds et al. 2007) were obtained from the NOAA National Climatic Data Center (www.ncdc.noaa.gov/thredds/catalog/oisst/Net CDF/AVHRR/catalog.html). These data represent daily SST estimates encompassing the entire study area at a spatial resolution of $0.25^{\circ}(\sim 110 \mathrm{~km}$ in the north-south direction, $\sim 71 \mathrm{~km}$ in the east-west direction). The data were imported into R 2.9.2 (R Development Core Team), and a script was developed to identify the closest marine pixel to each sample site. Lima \& Wethey (2012, their supplementary tables) showed that the nearest pixel to intertidal sites in this dataset is highly correlated to SST measured onshore. The resulting dataset was used to generate a table containing the number of days below $10^{\circ} \mathrm{C}$ at each sampling site during the predicted Semibalanus balanoides reproductive season for each year between 1983 and 2012. The reproductive season was estimated by subtracting the period between fertilization and larval release (110 to $120 \mathrm{~d}$, Crisp 1964) for $S$. balanoides in the UK from the range of dates of release (9 to 24 March, Crisp 1964). The $10^{\circ} \mathrm{C}$ temperature threshold was selected based on the findings of Barnes (1963) and Crisp \& Patel (1969) that $S$. balanoides requires a period of 4 to $6 \mathrm{wk}$ below this temperature for reproduction to occur. However, we do not expect this to be an allor-nothing response; reproductive output may be inversely proportional to temperature so long as winter temperatures fall below the temperature (10 to $12^{\circ} \mathrm{C}$ ) that inhibits reproduction (Drévès 2001,
Abernot-Le Gac et al. 2013). In addition, the potential role of air temperature in regulating reproductive output in $S$. balanoides is poorly known; thus, reproduction of some individuals within a population may be inhibited if they reside in warm microsites, while others, in cold microsites, may reproduce. Accordingly, we assigned each site to 1 of 3 categories: (1) if SST was $<10^{\circ} \mathrm{C}$ for more than $6 \mathrm{wk}$, we concluded that it is probable that adult $S$. balanoides would have high reproductive output; (2) if SST was below $10^{\circ} \mathrm{C}$ for 4 to $6 \mathrm{wk}$, we concluded that it is possible that barnacles at this site spawned and reproductive output was expected to be modest; and (3) if SST did not fall below $10^{\circ} \mathrm{C}$ for at least $4 \mathrm{wk}$, we concluded that it is likely that many adults at a site were inhibited from reproducing and that reproductive output was expected to be low that year.

\section{RESULTS}

Start Point, Southwest England (Fig. 1), can be a formidable barrier to water and larval transport (Gilg \& Hilbish 2003) and typically separates a region of comparatively cold water to the east from a region of warmer water to the west (see Figs. $2 \& 3$ ). Consequently, we report our results with respect to distance east and west of Start Point. In 2010, adult Semibalanus balanoides densities west of Start Point were low, with most sites having fewer than 0.5 adult ind. $\mathrm{cm}^{-2}$. Adult densities were generally higher east of Start Point, where 2 populations had adult densities that exceeded 2.5 ind. $\mathrm{cm}^{-2}$. During the winter of 2009 to 2010, all but the 2 westernmost sites experienced at least 6 wk below $10^{\circ} \mathrm{C}$, and these populations were categorized as having high reproductive output (Fig. 2A). At the 2 westernmost sites, SST was $<10^{\circ} \mathrm{C}$ for between 4 and $6 \mathrm{wk}$, and populations at these sites were expected to have medium reproductive output. S. balanoides recruitment density in 2009 to 2010 was very high, averaging $\sim 7$ ind. $\mathrm{cm}^{-2}$ at sites east of and up to $100 \mathrm{~km}$ west of Start Point. At sites 100 to $170 \mathrm{~km}$ west of Start Point, recruitment density declined to $\sim 3$ ind. $\mathrm{cm}^{-2}$, and no recruits were observed at the 2 westernmost sites (Fig. 2A).

During 2010 to 2011, temperatures were again cold, and 8 of the 14 sites were classified as having high reproductive output, while the 6 westernmost sites experienced between 4 and $6 \mathrm{wk}<10^{\circ} \mathrm{C}$ and were categorized as having medium reproductive potential. Semibalanus balanoides recruitment ranged from 0 to 6.61 ind. $\mathrm{cm}^{-2}$ (Fig. 2B). At sites 100 to $170 \mathrm{~km}$ west of Start Point, recruitment was again 

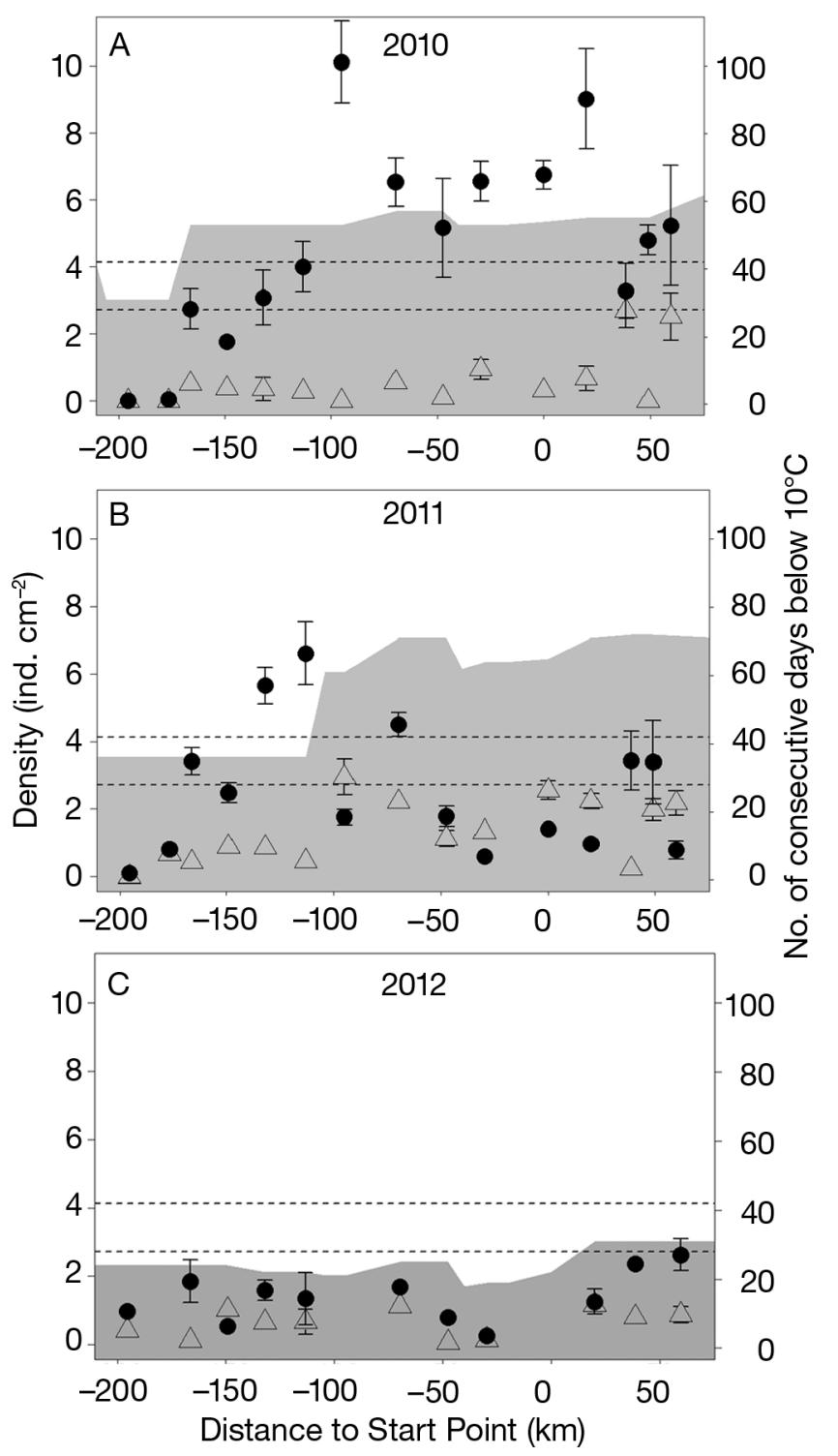

Fig. 2. Semibalanus balanoides. Young of the year $(\bullet)$ and adult $\left(\Delta\right.$ ) densities (ind. $\mathrm{cm}^{-2} \pm 1 \mathrm{SE}$ ) measured in (A) 2010, (B) 2011, and (C) 2012 and number of consecutive days below $10^{\circ} \mathrm{C}$ (shaded area) as a function of distance from Start Point, England. Dashed lines represent thresholds at 28 and $42 \mathrm{~d}$, delineating conditions under which high ( $>42 \mathrm{~d})$, medium ( 28 to $42 \mathrm{~d}$ ), and low $(<28 \mathrm{~d}$ ) reproductive output are predicted

high during 2011 and was significantly greater than recruitment during 2010 (Fig. 2B; Wilcoxon rank sum test, $\mathrm{p}<0.05)$. The 2 westernmost sites, which did not receive recruits in 2010, both received recruits in 2011, albeit at low density. At sites within $100 \mathrm{~km}$ of Start Point, there is no clear pattern; some sites exhibited greater recruitment in 2011 than in 2010, while others exhibited lower or similar recruitment density compared to 2010 .
Adult density was significantly greater in 2011 than in 2010 at all sites west of Start Point (Fig. 2B; Wilcoxon rank sum test, $\mathrm{p}<0.05$ ), except for the westernmost site, where adult density was zero in both years. At the 4 sites east of Start Point, adult density was significantly greater in 2011 than in 2010 at 3 sites and significantly lower at 1 site (Fig. 2B; Wilcoxon rank sum test, $p<0.05$ ). It is probable that this increase in adults in 2011 is the result of high recruitment in 2010 .

In contrast to the previous 2 years, SST during the winter of 2011 to 2012 was comparatively warm; no location within the study region experienced $>6 \mathrm{wk}$ of temperature below $10^{\circ} \mathrm{C}$, and only sites east of Start Point experienced 4 to 6 wk below $10^{\circ} \mathrm{C}$. Recruitment density was very low, averaging $\sim 1$ ind. $\mathrm{cm}^{-2}$ throughout the region. This low recruitment is in contrast to the increase in adult density that occurred at most sites as a result of high recruitment during the previous 2 yr. Semibalanus balanoides may mature within their first year if they experience rapid growth (Moore 1936, Southward 1967, Wethey 1985a); thus, both 1 yr old and older barnacles may contribute to adult reproduction if temperatures permit. It is striking that recruitment fails just as recruits from 2010 and 2011 mature into reproductively active adults.

To determine whether the density of YOY was explained by adult density within the settlement site, we compared YOY density to the adult density at each site by performing Pearson rank-order correlation tests. YOY and adult densities were not significantly correlated in any of the 3 years of this study (2010: $\mathrm{r}=0.128, \mathrm{p}=0.517 ; 2011 \mathrm{r}=-0.178, \mathrm{p}=0.511$; 2012: $\mathrm{r}=0.352, \mathrm{p}=0.217$ ), indicating that the density of local adults is insufficient to explain local recruitment patterns.

While it is clear that warm winter temperatures inhibit reproduction in Semibalanus balanoides, it is not certain that $10^{\circ} \mathrm{C}$ is necessarily the threshold for inhibiting reproduction; inhibitory temperature thresholds may occur either above or below $10^{\circ} \mathrm{C}$. We compared days below $10^{\circ} \mathrm{C}$ with days below $9^{\circ} \mathrm{C}$ and below $11^{\circ} \mathrm{C}$, and they were all highly correlated (in both cases $r=0.78, p<0.0001, d f=838$ ). Thus, while we used days below $10^{\circ} \mathrm{C}$ in the analyses reported here, this temperature is not necessarily a threshold, but it is correlated with other measures of winter temperature.

We analyzed winter SST from 1983 to 2012 (the extent of the Reynolds optimally interpolated V2 SST dataset) to determine the frequency and distribution of high, medium, and low reproductive output years 
for Semibalanus balanoides spawning in Southwest England (Fig. 3). At sites east of Start Point, high, medium, and low reproductive output years represented 44,23 , and $33 \%$ of the total years, respectively. Sites west of Start Point were typically warmer, with low reproductive output occurring in $56 \%$ of the years and years with high and medium reproductive output representing 26 and $17 \%$ of the total time period, respectively. The pattern of high, medium, and low reproductive output years varies through time (Fig. 3). Prior to 1998, high and medium output years were separated by 1 or 2 low output years. Since 1998, high and medium output years have occurred less frequently (Fig. 3) both east and west of Start Point and were separated by several years in a row where spawning was expected to be low. While there is no statistically significant correlation between number of cold days and time for the entire region ( $\mathrm{df}=28, \mathrm{r}=-0.20, \mathrm{p}=0.290$ ), if the recent 4 years (2009 to 2012) are removed, there is a significant negative correlation between number of cold days and time for sites east ( $\mathrm{df}=24, \mathrm{r}=-0.47, \mathrm{p}=0.016$ ) and west ( $\mathrm{df}=24, \mathrm{r}=-0.46, \mathrm{p}=0.018$ ) of Start Point.

\section{DISCUSSION}

The factors contributing to marine population connectivity are notoriously difficult to measure, and adult input to the larval pool is perhaps the most

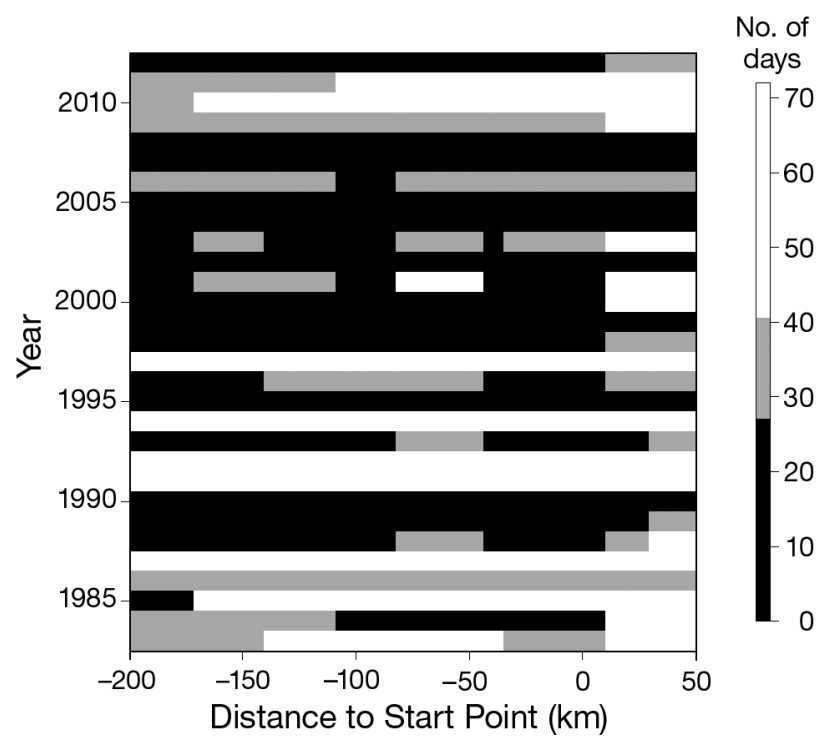

Fig. 3. Number of consecutive days below $10^{\circ} \mathrm{C}$ as a function of time and distance from Start Point, England, for 1983 to 2012. Color bar indicates the number of days below $10^{\circ} \mathrm{C}$. White, grey, and black regions respectively represent the expectation of high $\left(>42 \mathrm{~d}\right.$ below $\left.10^{\circ} \mathrm{C}\right)$, medium ( 28 to $42 \mathrm{~d}$ below $\left.10^{\circ} \mathrm{C}\right)$, and low $\left(<28 \mathrm{~d}\right.$ below $\left.10^{\circ} \mathrm{C}\right)$ reproductive output intractable component because it requires knowledge of the contribution of all potential source populations over large spatial scales. We took advantage of the fact that warm winter temperatures inhibit reproduction in Semibalanus balanoides to test the hypothesis that variation in adult contribution to the larval pool significantly influences connectivity among adult populations. In Southwest England, annual variation in SST determines the reproductive potential of adult populations over broad spatial scales and determines the magnitude of potential connectivity over the same geographic scales. Consequently, we expect adult contribution to the larval pool and subsequent larval recruitment to be much greater following cold winters where the threshold for reproduction has been met, and to be low following warm winters where the threshold has not been met (e.g. Wethey et al. 2011). This is precisely what we observed; following the cold winters of 2009 to 2010 and 2010 to 2011, high levels of recruitment occurred throughout most of Southwest England. The magnitude of larval recruitment was exceptional, especially in 2010, when recruitment was $~ 6$ to 10 ind. $\mathrm{cm}^{-2}$ at sites $100 \mathrm{~km}$ west of Start Point. Such high densities have not been observed in Southwest England for many years, especially at locations more than $50 \mathrm{~km}$ west of Start Point (Moore 1936, Southward 1991, Southward et al. 1995, Hawkins et al. 2003), and are comparable to high recruitment sites elsewhere in Europe, near the center of the species' range distribution, where adult population density is much higher (Connell 1985, Wethey 1985b, Jenkins et al. 2000, 2001). In contrast, following the warm winter of 2011 to 2012, we observed low recruitment throughout Southwest England. The prediction that cold winters that exceeded the reproductive threshold of 4 to $6 \mathrm{wk}$ below $10^{\circ} \mathrm{C}$ would result in increases in adult provisioning of the larval pool is therefore strongly supported.

Jenkins et al. (2000) described larval settlement and recruitment of Semibalanus balanoides at 3 sites 6 to $40 \mathrm{~km}$ west of Start Point. In 1997, following a cold winter that met the criterion for high reproduction (Fig. 3), they observed high levels of larval recruitment ( $\sim 6$ to 8 ind. $\mathrm{cm}^{-2}$ ) comparable to our observations in 2010. In 1998, following a warm winter during which the reproduction was expected to be inhibited at sites west of Start Point (Fig. 3), they observed negligible recruitment. If we combine these results with ours, we find that in 3 of the 5 years, we predicted and observed high recruitment success and that in the remaining 2 years, we predicted and observed recruitment failure. The proba- 
bility of obtaining this result in the correct sequence is $0.035(3 / 5 \times 2 / 5 \times 3 / 5 \times 3 / 5 \times 2 / 5)$; thus, it is unlikely that we would have observed the predicted sequence of recruitment success and failure by chance alone. The results of Jenkins et al. (2000) endorse the hypothesis that the adult provisioning of the larval pool drives larval recruitment and that this, in turn, depends on temperature falling below the $10^{\circ} \mathrm{C}$ threshold for at least 4 to $6 \mathrm{wk}$ during the winter.

In this study, we measured larval recruitment within 2 mo of larval settlement; thus, it is possible that post-settlement mortality affected the abundance of juvenile barnacles (Connell 1985, Pineda et al. 2009, 2010) prior to our measuring YOY densities. Jenkins et al. (2000) compared annual and spatial variation in settlement and recruitment at multiple spatial scales across Europe. They found settlement and recruitment to be highly correlated within 3 of 4 regions studied across Europe, and in Southwest England, $99 \%$ of the variation in recruitment among sites and between years could be explained by the level of settlement. Thus, we believe our assessment of annual variation in recruitment accurately reflects variation in larval settlement rate.

Bertness et al. (1991), Leslie et al. (2005), and Burrows et al. (2010) report that regional primary production (as measured by chl a concentration) contributes to variation in growth and reproductive output in barnacles. It is possible that the annual variation in recruitment observed in Southwest England is from the variation in primary production that is correlated with winter SST. We tested this possibility by comparing annual variation in primary production to the recruitment of Semibalanus balanoides observed by us and by Jenkins et al. (2000). Primary production was measured by in situ fluorometry at a station within $10 \mathrm{~km}$ of sample sites used in this study and by Jenkins et al. (2000) (www.westernchannelobservatory.org.uk). We averaged weekly total chl a concentration between May 1 and November 1 prior to the measurement of recruitment as an estimate of the period over which $S$. balanoides accumulates reserves for growth and reproduction (between settlement in mid-April and egg deposition in November). Primary production and recruitment were not significantly correlated ( $\mathrm{r}=0.0005)$; in fact, the period of highest primary production corresponded to the year with lowest recruitment. We also compared recruitment to the average concentration of chl a in March of the year recruitment was measured to assess whether barnacle larvae in the plankton may survive better in years with high primary production. There was again no significant correla- tion $(r=0.09)$, and the year with the highest primary production in March corresponded to the second lowest recruitment. Thus, there is no evidence that annual variation in primary production contributes to the observed annual variation in recruitment in Southwest England.

Variation of larval input driven by variation in winter temperature provides a mechanism for the longobserved pattern of oscillating population size of Semibalanus balanoides in Southwest England (Moore 1936, Southward \& Crisp 1954, Southward 1967, 1991, Southward et al. 1995, Hawkins et al. 2003). Prior to 2010, adult $S$. balanoides were rare or absent from locations west of Start Point (Fig. 2A), but this has not always been the case. S. balanoides was a dominant intertidal species in the 1930s and 1940s, declined to become rare in the late 1940s and early 1950s when the western English Channel warmed, enjoyed a rebound during a cold period from 1952 to 1957, declined again as SST warmed between 1958 and 1961, became abundant again during rapid cooling in the early 1960s, and then has continuously declined during the current warming trend that began in the 1980s (Moore 1936, Southward \& Crisp 1954, Southward 1967, Southward et al. 1995, Hawkins et al. 2003). Parallel fluctuations occurred on the continental coast of Europe during the same period (Wethey et al. 2011). Thus, the high levels of larval recruitment observed in 2010 and 2011 and the resurgence of adults observed in 2011 and 2012 occur against a backdrop of regional rarity of $S$. balanoides that has persisted for several decades. Our data indicate that whether winter temperatures drop below the reproductive threshold for a sufficient duration is a key component of the reproductive success of $S$. balanoides and that this, in turn, determines the size of the larval pool available for settlement and recruitment.

The origins of the larvae that recruited in 2010 and 2011 are unclear. In this study, we observed a westward expansion of Semibalanus balanoides into Southwest England in 2010 and further to the west again in 2011. Southward (1967) also observed a westward expansion of $S$. balanoides during a cold period in the early 1960s. Southward (1967) reported that the 'main front' of $S$. balanoides moved an average of $53 \mathrm{~km} \mathrm{yr}^{-1}$ and a maximum of $\sim 120 \mathrm{~km} \mathrm{yr}^{-1}$. Similar rates of expansion of the geographic range of $S$. balanoides occurred on the continental European coast after the cold winter of 2010 (Wethey et al. 2011). In Southwest England, dense populations of adults only occurred east of Start Point in 2010, so it is likely that larvae produced by these populations 
were dispersed to the west. During the dispersal period for S. balanoides (March to April), near-shore currents in Southwest England are driven westward by strong easterly winds (Pingree \& Griffiths 1980). In 2011, recruitment advanced further westward, which may suggest that the larvae transported to these western sites were produced by adults that were established west of Start Point in 2010 (Fig. 2). These results all indicate that the western sites are connected to and depend on recruitment from populations to the east; however, bulk transport of barnacle larvae over such large distances seems unlikely, especially given that this would require transport around Start Point, which has previously been shown to be a formidable barrier to larval dispersal (Gilg \& Hilbish 2003). Physical circulation modeling for the years of our study is ongoing and may reveal that Start Point is a less formidable barrier to larval dispersal than previously suggested (Gilg \& Hilbish 2003). Alternatively, westward expansion may originate from refuge populations in the west, as small numbers of adults were indeed present west of Start Point prior to 2010. Southward (1967) also suggested that refuge populations may be important for repatriation of western sites. However, this is unlikely to be the sole explanation of the westward expansion; the temperature patterns were similar in 2010 and 2011, with all sites in the study region classified as having high or moderate reproductive output, but recruitment at the westernmost sites only occurred in 2011. If the recruitment patterns were based solely on cold temperatures allowing the reproduction of refuge populations, we would expect a similar recruitment pattern in both cold years, not the advancing front that was observed. It is also possible that the advancing front was generated by a combination of larvae from the east and advancing cold from the east allowing reproduction by refuge populations, but current data do not allow us to differentiate between these hypotheses or some combination of the two.

The observed pattern of permissive vs. nonpermissive years of reproduction (Fig. 3) has population-wide implications for Semibalanus balanoides in Southwest England. The average lifespan of $S$. balanoides is 3 yr (Southward \& Crisp 1954, Wethey 1985a), so local extinction of $S$. balanoides will likely occur in areas that are not reseeded with larvae at least once every 3 yr. Local extinction resulting from lack of larval settlement likely produced the dearth of $S$. balanoides in areas west of Start Point prior to 2010. Over the past 2 decades, there has been a significant decline in the annual number of cold days (excluding the 2 recent cold winters) and an increase in the number of years in which reproduction should be inhibited, separating years with high or modest reproductive output. Thus, we predict that populations of $S$. balanoides in Southwest England will remain transient. In addition, data from both Southward (1967) and our study indicate that a single cold year is insufficient for larvae to colonize the far western sites. If the frequency of inhibitory years continues to increase, these areas may permanently be outside of the range of $S$. balanoides, and the species' range will contract significantly. The Wethey et al. (2011) metapopulation model predicted that $S$. balanoides would disappear from Southwest England by 2099 under the Intergovernmental Panel on Climate Change (IPCC) A1B climate change scenario. Following a similar climate scenario, Poloczanska et al. (2008) predicted regional extinction by 2060. Our results suggest that $S$. balanoides could disappear from Southwest England even sooner and may require less warming than Poloczanska et al. (2008) and Wethey et al. (2011) suggest.

Semibalanus balanoides populations in Southwest England highlight the combined roles of connectivity and adult input into the larval pool as controlling forces in population dynamics. In these populations, local recruitment is not significantly correlated with local adult density, indicating that their demography is likely a regional process mediated by population connectivity. Although input into the larval pool is an understudied component of connectivity, the few studies that have simultaneously measured recruitment and adult input indicate that recruitment variation is strongly related to adult density (Smith et al. 2009) and adult fecundity (Hughes et al. 2000, Reed et al. 2009, Burrows et al. 2010). In contrast, Leslie et al. (2005) found that regional primary production influenced barnacle growth and reproductive output but had little apparent impact on recruitment. Together these examples indicate that variation in input into the larval pool can drive variation in connectivity and illustrate the need to incorporate variation in larval pool input into models of marine population connectivity. They also illustrate the need for a mechanistic understanding of the forces generating variation in adult input into the larval pool; in the study by Smith et al. (2009), recruitment was correlated with upstream adult biomass, while in Hughes et al. (2000) adult abundance only explained $1.2 \%$ of the variation in recruitment and fertility accounted for $72 \%$ of the variance.

A striking commonality between this study and those by Hughes et al. (2000), Smith et al. (2009), Reed et al. (2009), and Burrows et al. (2010) is that in 
all cases, a significant relationship was found between adult inputs into the larval pool and recruitment, even though these studies placed little emphasis on measuring, or even identifying, the other forces that potentially shape population connectivity between larval release and recruitment. Overall, input into the larval pool plays a key role in population connectivity, as it provides the initial starting conditions for subsequent modification by other factors (physical transport, mortality, behavior). Realistic variation in larval pool input needs to be incorporated into existing models of population connectivity to understand the magnitude of the signal generated by these other factors and their relative effect on the density of larvae inputted by adults and subsequent connectivity in populations.

Acknowledgements. This work was funded by NSF (OCE1039513, OCE1129401), NASA (NNX07AF20G, NNX11AP$77 \mathrm{G})$, and the Elsie Taber Graduate Fellowship Fund of the University of South Carolina. We thank P. Lindeque, E. Fileman, and F. Staff, all affiliated with the Plymouth Marine Laboratory, for support in the field. We also thank 3 anonymous reviewers for their insightful comments on an earlier version of this manuscript.

\section{LITERATURE CITED}

Abernot-Le Gac C, Antajan E, Devreker D, Drévès L and others (2013) Surveillance écologique et halieutique du site électronucléaire de Flamanville. Année 2012, rapport scientifique annuel. Rapport IFREMER RST LER/ BO/13.004 http://archimer.ifremer.fr/doc/00139/24998/ 23096.pdf (accessed 1 Apr 2013)

Abramoff MD, Magalhães PJ, Ram SJ (2004) Image processing with ImageJ. Biophotonics Int 11:36-42

Barnes H (1957a) Processes of restoration and synchronization in marine ecology. The spring diatom increase and the 'spawning' of the common barnacle, Balanus balanoides (L.). Annee Biol 33:67-85

Barnes H (1957b) The northern limits of Balanus balanoides (L.). Oikos 8:1-15

Barnes H (1963) Light, temperature and the breeding of Balanus balanoides. J Mar Biol Assoc UK 43:717-727

Becker BJ, Levin LA, Fodrie FJ, McMillan PA (2007) Complex larval connectivity patterns among marine invertebrate populations. Proc Natl Acad Sci USA 104: 3267-3272

> Bertness MD, Gaines SD, Bermudez D, Sanford E (1991) Extreme spatial variation in the growth and reproductive output of the acorn barnacle Semibalanus balanoides. Mar Ecol Prog Ser 75:91-100

Burrows MT, Jenkins SR, Robb L, Harvey R (2010) Spatial variation in size and density of adult and post-settlement Semibalanus balanoides: effects of oceanographic and local conditions. Mar Ecol Prog Ser 398:207-219

Carson HS, Cook GS, López-Duarte PC, Levin LA (2011) Evaluating the importance of demographic connectivity in a marine metapopulation. Ecology 92:1972-1984
Connell JH (1985) The consequences of variation in initial settlement vs. post-settlement mortality in rocky intertidal communities. J Exp Mar Biol Ecol 93:11-45

> Crisp DJ (1964) Racial differences between North American and European forms of Balanus balanoides. J Mar Biol Assoc UK 44:33-45

> Crisp DJ, Clegg DJ (1960) The induction of the breeding condition in Balanus balanoides. Oikos 11:265-275

> Crisp DJ, Patel B (1969) Environmental control of the breeding of three boreo-arctic cirripedes. Mar Biol 2:283-295

Drévès L (2001) Effets climatiques sur les écosystèmes marins. Exemple du recrutement des crustacés cirripèdes sur la côte ouest du Cotentin. Hydroécologie Appliquée 13:101-112

Gilg MR, Hilbish TJ (2003) The geography of marine larval dispersal: coupling genetics with fine-scale physical oceanography. Ecology 84:2989-2998

> Hawkins SJ, Southward AJ, Genner MJ (2003) Detection of environmental change in a marine ecosystem-evidence from the western English Channel. Sci Total Environ 310:245-256

> Hughes TP, Baird AH, Dinsdale EA, Moltschaniwskyj NA, Pratchett MS, Tanner JE, Willis BL (1999) Patterns of recruitment and abundance of corals along the Great Barrier Reef. Nature 397:59-63

> Hughes TP, Baird AH, Dinsdale EA, Moltschaniwskyj NA, Pratchett MS, Tanner JE, Willis BL (2000) Supply-side ecology works both ways: the link between benthic adults, fecundity, and larval recruits. Ecology 81:2241-2249

> Jenkins SR, Åberg P, Cervin G, Coleman RA and others (2000) Spatial and temporal variation in settlement and recruitment of the intertidal barnacle Semibalanus balanoides (L.) (Crustacea: Cirripedia) over a European scale. J Exp Mar Biol Ecol 243:209-225

Jenkins SR, Åberg P, Cervin G, Coleman RA and others (2001) Population dynamics of the intertidal barnacle Semibalanus balanoides at three European locations: spatial scales of variability. Mar Ecol Prog Ser 217:207-217

Leslie HM, Breck EN, Chan F, Lubchenco J, Menge BA (2005) Barnacle reproductive hotspots linked to nearshore ocean conditions. Proc Natl Acad Sci USA 102: 10534-10539

> Levin LA (2006) Recent progress in understanding larval dispersal: new directions and digressions. Integr Comp Biol 46:282-297

- Lima FP, Wethey DS (2012) Three decades of highresolution coastal sea surface temperatures reveal more than warming. Nat Commun 3:704

McGuinness KA, Davis AR (1989) Analysis and interpretation of the recruit-settler relationship. J Exp Mar Biol Ecol 134:197-202

> Menge BA (2000) Recruitment vs. postrecruitment processes as determinants of barnacle population abundance. Ecol Monogr 70:265-288

> Minchinton TE, Scheibling RE (1991) The influence of larval supply and settlement on the population structure of barnacles. Ecology 72:1867-1879

> Moore HB (1936) Biology of Balanus balanoides. V. Distribution in the Plymouth area. J Mar Biol Assoc UK 20: 701-716

> Nathan R (2001) The challenges of studying dispersal. Trends Ecol Evol 16:481-483

> Pineda J, Reyns NB, Starczak VR (2009) Complexity and simplification in understanding recruitment in benthic populations. Popul Ecol 51:17-32 
Pineda J, Porri F, Starczak VR, Blythe J (2010) Causes of decoupling between larval supply and settlement and consequences for understanding recruitment and population connectivity. J Exp Mar Biol Ecol 392:9-21

Pingree RD, Griffiths DK (1980) Currents driven by a steady uniform wind stress on the shelf seas around the British Isles. Oceanol Acta 3:227-236

Poloczanska ES, Hawkins SJ, Southward AJ, Burrows MT (2008) Modeling the response of populations of competing species to climate change. Ecology 89:3138-3149

R Development Core Team (2009) R: a language and environment for statistical computing. R Foundation for Statistical Computing, Vienna. www.r-project.org

Reed DC, Holbrook SJ, Blanchette CA, Worcester S (2009) Patterns and sources of variation in flowering, seed supply and seedling recruitment in surfgrass Phyllospadix torreyi. Mar Ecol Prog Ser 384:97-106

Reynolds RW, Smith TM, Liu C, Chelton DB, Casey KS, Schlax MG (2007) Daily high-resolution-blended analyses for sea surface temperature. J Clim 20:5473-5496

Rumrill SS (1990) Natural mortality of marine invertebrate larvae. Ophelia 32:163-198

Smith GK, Guichard F, Petrovi F, McKindsey CW (2009) Spatial statistics to infer scales of demographic connectivity between populations of the blue mussel, Mytilus spp. Limnol Oceanogr 54:970-977

Southward AJ (1967) Recent changes in abundance of intertidal barnacles in south-west England: a possible effect of climatic deterioration. J Mar Biol Assoc UK 47:81-95

Southward AJ (1976) On the taxonomic status and distribu-

Editorial responsibility: James McClintock,

Birmingham, Alabama, USA tion of Chthamalus stellatus (Cirripedia) in the north-east Atlantic region: with a key to the common intertidal barnacles of Britain. J Mar Biol Assoc UK 56:1007-1028

> Southward AJ (1991) Forty years of changes in species composition and population density of barnacles on a rocky shore near Plymouth. J Mar Biol Assoc UK 71:495-513

> Southward AJ, Crisp DJ (1954) Recent changes in the distribution of the intertidal barnacles Chthamalus stellatus Poli and Balanus balanoides L. in the British Isles. J Anim Ecol 23:163-177

Southward AJ, Crisp DJ (1963) Barnacles of European waters. Catalogue of main marine fouling organisms, Vol. 1: Barnacles. Organisation for Economic Co-operation and Development Publications, Paris

Southward AJ, Hawkins SJ, Burrows MT (1995) Seventy years' observations of changes in distribution and abundance of zooplankton and intertidal organisms in the western English Channel in relation to rising sea temperature. J Therm Biol 20:127-155

- Wethey DS (1985a) Catastrophe, extinction, and species diversity: a rocky intertidal example. Ecology 66:445-456

Wethey DS (1985b) Local and regional variation in settlement and survival in the littoral barnacle Semibalanus balanoides (L.): patterns and consequences. In: Moore PG, Seed R (eds) The ecology of rocky coasts. Hodder and Stoughton, London, p 194-202

> Wethey DS, Woodin SA, Hilbish TJ, Jones SJ, Lima FP, Brannock PM (2011) Response of intertidal populations to climate: effects of extreme events versus long term change. J Exp Mar Biol Ecol 400:132-144

Submitted: July 17, 2013; Accepted: October 2, 2013

Proofs received from author(s): December 19, 2013 